\title{
From fluid inclusion microanalysis to large-scale hydrothermal mass transfer in the Earth's interior
}

\author{
Christoph A. HEINRICH \\ Isotope Geochemistry and Mineral Resources, Department of Earth Sciences, \\ ETH Zürich 8092 Zürich, Switzerland
}

\begin{abstract}
This paper illustrates how the recent development of microanalytical techniques for major- and trace-elements in fluid and melt inclusions contributes to the quantitative understanding of lithosphere-scale chemical transport by hydrothermal fluids, including the formation of mineral deposits. After an introductory remark on aspects of instrumentation and data quality assessment, the first-order controls of crustal fluid compositions are discussed, indicating that trace-element concentrations broadly follow silicate rock buffered conditions. However, field-based studies of texturally controlled ore-forming liquid and vapour inclusions in specific upper-crustal magmatic centres show that effective ore formation is a disequilibrium process, requiring deviations of fluid composition from the crustal rock buffers. Microanalytical techniques are also changing experimental approaches in the laboratory, allowing fluid trapping experiments for investigating mineral solubilities, melt-fluid distribution constants, and the chemical properties of fluids responsible for selective element transfer from the downgoing slab to the melting region of calc-alkaline magmas in the mantle wedge.
\end{abstract}

Keywords: Fluid, Inclusion, Microanalysis, LA-ICPMS, Ore deposits, Subduction

\section{INTRODUCTION}

The last decade has seen a trend of increasing combination of experimental as well as field-based studies of mineral-fluid interaction with a range of new technical developments for characterising fluid microsamples in situ, i.e., as individual inclusions trapped in their petrographic context of natural and synthetic host minerals. The principles of three currently used techniques, their diverse quantification approaches and their advantages and limitations have been reviewed elsewhere (e.g., Heinrich et al., 2003 focussing on Laser Ablation ICPMS; Ryan, 2004 and Dietrich et al., 2000 on PIXE and PIGE by nuclear microprobe; Vanko et al., 2001 and Cauzid et al., 2004 on Synchrotron XRF). This review illustrates how microanalysis of natural and synthetic fluid samples, mostly by LA-ICPMS, has contributed to our present understanding of hydrothermal mass transfer in the active plate margin environment. Here, the interaction of chemically complex 'fluids' - including silicate and sulfide melts, brines and aqueous solutions of variable density - lead to large-scale mass transfer from the slab through the mantle, crustal magmas and volcanoes to the hydrosphere.

C.A. Heinrich, heinrich@erdw.ethz.ch Corresponding author

\section{MICROANALYTICAL TECHNIQUES AND DATA RELIABILITY}

An essential requirement applying to all three microanalytical techniques is the estimation of realistic analytical uncertainty. Even though all three techniques for elemental analysis permit quantification of elemental concentrations to a precision of a few percent in favourable cases, the accuracy by which a geological paleo-fluid can be compositionally characterised depends not only on technical limitations (e.g., knowledge of an internal standard and microthermometric phase relations, required to quantify concentrations by LA-ICPMS), but even more on the basic limitations imposed by individual samples. As with conventional fluid inclusion research, interpretable data requires microanalysis of several individual inclusions in each cogenetic assemblage (e.g., a particular growth zone or a single healed fracture trail), such that the consistency of results can be checked and realistic standard deviations from an average can be calculated (e.g. Günther et al, 1998; Landtwing et al., 2005). Reporting data from multiple inclusions in each assemblage is the only method of assessing the reliability and estimating the uncertainty of fluid compositions, both in natural and experimental samples. Experience from more than a thousand inclusion 
analyses published by our lab since 1998 show that relative and absolute uncertainties obtained by LA-ICPMS may be as low as a 3\% (e.g., Simon et al., 2004; see also Allan et al., 2005), but are more commonly ten times larger due to imperfect sampling, low and irregular signal intensity, complex inclusion geometry or imperfect inclusion preservation (Heinrich et al., 2003). Apparent compositional variations may even be completely spurious due to heterogeneous trapping or postentrapment modification of inclusions.

Therefore, no fluid inclusion data (including conventional microthermometry) should be published unless the consistency of results within specified assemblages of coeval inclusions is explicitly reported. In light of our experience with LA-ICPMS and micro-PIXE, petrographic study of samples prior to microanalysis, good viewing optics permitting targeted analysis of the previously selected inclusions, and low cost and high efficiency for carrying out numerous analyses on each sample are essential success factors for generating geologically meaningful results.

\section{MASTER VARIABLES CONTROLLING HYDROTHERMAL ELEMENT TRANSPORT AT CRUSTAL SCALE}

Fluid-rock reactions able to alter the composition of crustal rocks on a large scale are dominated by cation exchange reactions such as

$$
\mathrm{KAlSi}_{3} \mathrm{O}_{8}(\mathrm{ksp})+\mathrm{Na}^{+}=\mathrm{NAlSi}_{3} \mathrm{O}_{8}(\mathrm{plg})+\mathrm{K}^{+}
$$

and

$$
\begin{aligned}
& 3 \mathrm{KAlSi}_{3} \mathrm{O}_{8}(\mathrm{ksp})+2 \mathrm{H}^{+}=\mathrm{KAl}_{3} \mathrm{Si}_{3} \mathrm{O}_{10}(\mathrm{OH})_{2}(\mathrm{mus}) \\
& +6 \mathrm{SiO}_{2}(\mathrm{qz})+2 \mathrm{~K}^{+} .
\end{aligned}
$$

Equation (2) exemplifies a type of common silicate hydrolysis or cation/acid exchange reactions, which can alter the compositions of rocks from deep crustal metasomatism to surficial weathering. The same cation-exchange and hydrolysis equilibria also act as buffers for the majorelement composition of crustal fluids, including their $\mathrm{pH}$, by equilibrium with the common rock-forming silicates. Mass balance constraints and fluid/mineral buffer reactions like (1) and (2) impose that saline (i.e., $\mathrm{Na}^{+}$- and $\mathrm{Cl}^{-}$ rich) fluids in equilibrium with silicate rocks are relatively more acid than similarly buffered low-salinity fluids. In addition to the effect of complexation with $\mathrm{Cl}^{-}$ligands, this $\mathrm{pH}$ effect leads to a steeply exponential increase of the solubility of most accessory minerals, including those hosting economically important base metals like Fe, Mn,
$\mathrm{Cu}, \mathrm{Pb}$ and $\mathrm{Zn}$ (Hemley et al., 1992).

Yardley (2005) recently presented a compilation of crustal fluid compositions, ranging from directly sampled fluids in recent sedimentary basins and active geothermal systems, to deep crustal fluids in metamorphic and magmatic environments represented by analyses of fluid inclusions. The results show broadly linear trends in $\log -$ concentration versus inverse temperature space, as summarised by the shaded areas in Figure 1. They illustrate a rather simple, first-order control of major and trace-metal concentrations, including $\mathrm{Fe}, \mathrm{Zn}, \mathrm{Cu}$ and other chloridecomplexed metals on temperature and fluid salinity. As expected from fluid buffering by common crustal rocks, temperature and chloride content are two "master variables' for hydrothermal metal transport in the crust. This leads to the important conclusion that all crustal fluids have the potential of becoming effective ore-forming fluids, although hot chloride-rich ones are orders of magnitude more effective than cool ones of low salinity. The importance of chloride emphasises the requirement of evaporitic sources of salinity in low-temperature environments, which can persist through geological periods, giving rise to global $\mathrm{Pb}-\mathrm{Zn}$ ore provinces for example. Mineral deposits are therefore not 'anomalous' in the sense of requiring uniquely specialised fluid sources (Yardley, 2005). However their formation requires a combination of physical and chemical fluid evolution paths that deviate from the general trend of crustal rock buffering.

\section{ORE DEPOSITS: DEVIATIONS FROM CRUSTAL EQUILIBRIUM}

Microanalysis of fluid inclusion assemblages in geological context has, over the last decade or so, allowed a new approach to the quantitative reconstruction of ore-forming processes in space and time. A key to utilising the technological advance of the new analytical instrumentations lies in systematic petrographic observations at all scales, to deduce the relative timing of fluid entrapment within the overall evolution of hydrothermal systems. Besides field geology and conventional petrography, cathodoluminescence imaging of crystal-growth features has made a major impact on understanding the successive trapping of fluid inclusion assemblages (Rusk and Reed, 2002; Redmond et al., 2004).

A number of integrated studies of ore-forming magmatic hydrothermal systems associated with acid to intermediate-composition volcano-plutonic centres have shown that salinity variations and temperature decrease are indeed major factors contributing to the formation of ore deposits. In addition however, the accumulation of metals to generate an economic resource requires a suc- 

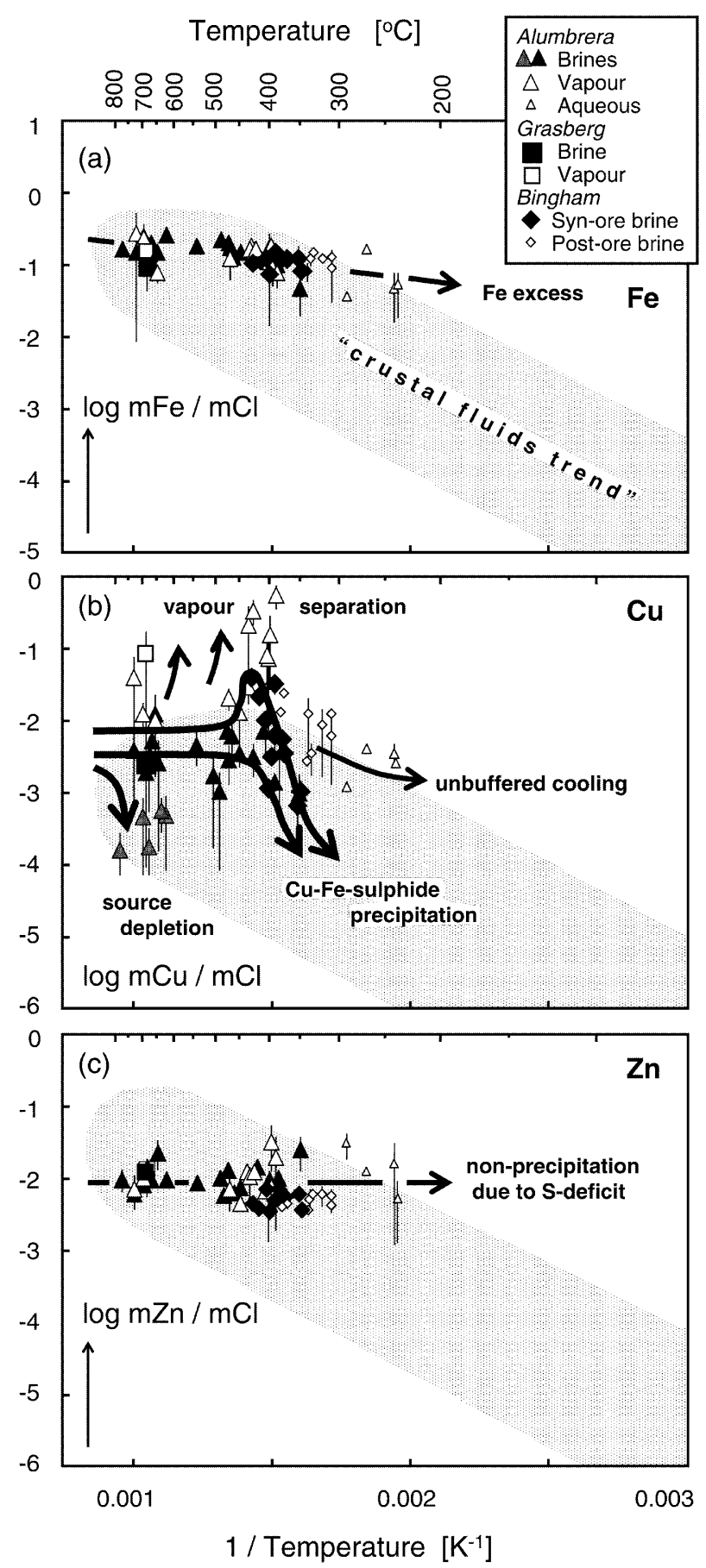

Figure 1. Concentration ratios of three metals, major Fe and minor to trace elements $\mathrm{Cu}$ and $\mathrm{Zn}$, from petrographically defined fluid inclusion assemblages in three porphyry-style ore deposits, plotted on a backdrop of the broad crustal buffering trends shown by Yardley (2005; shaded area). Note that each point symbol represents an average and $1 \sigma$ standard deviation (indicated by error bars where larger than symbol size) from several individual inclusions, each analysed by combination of microthermometry and LA-ICPMS microanalysis. Data from Ulrich et al. (1999, 2001) and Landtwing et al. (2005). cession of processes, in which structurally focussed fluids experience steep gradients in physicochemical parameters, leading to a high degree of disequilibrium between the large-scale metal-transporting environment and the local ore-depositing conditions.

Disequilibrium processes contributing to ore formation include physical separation of multiple fluids (melts, aqueous liquid, vapour) from one another (i.e., by exsolution, boiling or condensation), the isolation of cooling fluids from wall-rock buffers along parts of their flow path, and the transfer of fluids between chemically contrasting rock reservoirs (notably with regard to redox potential and sulphur availability). In addition, the steep temperature dependence in ore metal solubility means that metal concentrations in hot metamorphic and magmatic-hydrothermal fluids are commonly limited by metal availability, rather than by mineral solubility. The next two sections summarise some data illustrating how deviations from the rock-buffered trends of metal concentration are essential for the formation of major magmatic-hydrothermal ore deposits.

\section{SELECTIVE METAL DEPOSITION IN MAGMATIC-HYDROTHERMAL SYSTEMS}

The composition of magmatic-hydrothermal fluids prior to modification by ore mineral deposition is primarily controlled by the metal contents of silicate melts and by melt/fluid partition coefficients during fluid exsolution from magmas, rather than by solubility equilibria. Thus, magma characteristics and initial fluid composition are the first-order controls on the provinciality of metal ratios, for example among $\mathrm{Cu}, \mathrm{Au}$ and Mo deposits. In several porphyry-copper deposits, illustrated by the point symbols in Figure 1, Ulrich et al. (1999; Bajo de la Alumbrera $\mathrm{Cu}-\mathrm{Au}$ ), Landtwing et al. (2005; Bingham $\mathrm{Cu}-\mathrm{Mo}^{-} \mathrm{Au}$ ) and also Klemm et al., (2006: Questa Mo) found that the $\mathrm{Cu}$ as well as all other metal concentrations (or metal/Cl molar ratios) of single-phase fluids and high-salinity brines initially remain constant over a large cooling interval from $>700{ }^{\circ} \mathrm{C}$ to $\sim 400{ }^{\circ} \mathrm{C}$ within one pulse of magmatic-hydrothermal ore formation, but $\mathrm{Cu} / \mathrm{Cl}$ decreases to a lower level in a late intrusion postdating the main mineralising one at Alumbrera (P2; Proffett, 2003), possibly due to $\mathrm{Cu}$ depletion of the subjacent magma reservoir (Fig. 1b; Halter et al., 2005). On cooling, the copper-rich magmatic fluids initially remain undersaturated in base metals due to the high solubility of all $\mathrm{Cu}-\mathrm{Mo}-\mathrm{Pb}-\mathrm{Zn}-\mathrm{Mn}$-minerals at high temperature. Only $\mathrm{Fe} / \mathrm{Cl}$ decreases throughout the cooling range, but follows a much flatter trend than the general rock-buffered path, because magnetite deposition from the very 
$\mathrm{FeCl}_{2}$-rich fluids is restrained by limited availability of an oxidant (being $\mathrm{SO}_{2}$ in this case; Ulrich et al., 2001).

Competing chemical reactions upon subsequent fluid cooling lead to highly selective deposition, of only specific metals. Others remain at constant concentration, with the fluid even becoming progressively undersaturated with the respective ore minerals despite cooling over hundreds of degrees. This was first shown by selective cassiterite precipitation due to fluid dilution, from a magmatic brine containing constant and much higher metal/Cl contents of non-precipitating $\mathrm{Cu}, \mathrm{Pb}$ and $\mathrm{Zn}$, compared with Sn saturating as cassiterite (Audétat et al., 1998). Figure $1 \mathrm{~b}$ and $\mathrm{c}$ illustrate selective ore metal deposition in porphyry copper deposits. The data by Ulrich et al. (2001; Bajo de la Alumbrera, Argentina) and Landtwing et al. (2005; Bingham Canyon, USA) show that $\mathrm{Cu}$ concentrations in texturally early high-salinity brines first remain constant over a large range in temperature $\left(\sim 780-420^{\circ} \mathrm{C}\right)$, and then steeply drop over 2-3 orders of magnitude due to $\mathrm{Cu}-\mathrm{Fe}$-sulfide precipitation over a small cooling interval from 420 to $350{ }^{\circ} \mathrm{C}$. The temperature-dependence in the Bingham data is steeper than the general rock-buffered trend but parallel to experimentally determined solubility contours (Hemley et al., 1992; Hezarkhani et al. 1999). By contrast, $\mathrm{Zn}$ (and also $\mathrm{Pb}, \mathrm{Mn}$ and numerous other analysed elements including alkalies) remain constant and do not precipitate. The brine will, in fact, never reach sphalerite and galena saturation, due the competition with $\mathrm{Cu}$ and $\mathrm{Fe}$ for the limited (and decreasing) concentration of sulphur available in the fluid, unless the contained base metals are transported to an external source of sulphur at low temperature.

\section{FLUID - FLUID SEPARATION AS A GEOCHEMI- CAL DIFFERENTIATION PROCESS}

Fluid inclusion analyses from porphyry-style and spatially related epithermal gold deposits illustrate the role of fluid phase separation in selective metal transport and ore formation. Microanalysis of saline liquid inclusions and low-salinity, low-density vapour inclusions, trapped together on single grow zones or healed fracture planes (so-called 'boiling assemblages'; Fig. 2), show that both fluids carry appreciable metal concentrations, and that some elements including $\mathrm{Cu}, \mathrm{As}, \mathrm{B}$ and $\mathrm{Au}$ can be even systematically enriched in the vapour phase (Heinrich et al., 1992; Audétat et al., 1998; Heinrich et. al., 1999; large open symbols in Fig. 1). Highly variable distribution coefficients of $\mathrm{Cu} / \mathrm{Cl}$ between brine and vapour in different boiling assemblages indicate that complexation with volatile sulphur ligands may dominantly contribute to the preferential partitioning of $\mathrm{Cu}$ and $\mathrm{Au}$ into the vapour phase,

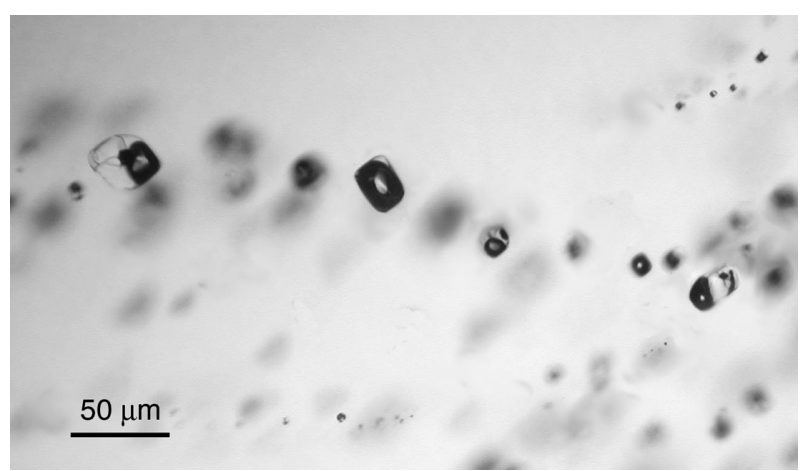

Figure 2. Photomicrograph of a single trail (healed crack) of inclusions that originally trapped two coexisting homogeneous phases in quartz: a low-density vapour phase (leading to inclusions with a large bubble and very little liquid after cooling; e.g., large inclusion in centre) and a higher-density brine (leading to inclusions with a smaller bubble and internally precipitated halite, sylvite and small opaque crystals; e.g. largest inclusion left). LAICPMS showed that the vapour is relatively enriched in $\mathrm{Cu}$, while the brine is rich in $\mathrm{Na}, \mathrm{K}, \mathrm{Fe}, \mathrm{Pb}, \mathrm{Zn}$ and many other chloride salt components (Los Pelambres porphyry copper deposit, Chile; unpublished photo by Leo Klemm).

while the brine is enriched with chloride-complexed metals and becomes relatively depleted in volatile sulphur. In conjunction with a recent experimental re-evaluation of vapour solubility of various metals (Williams-Jones et al., 2002), these data have led to a major re-interpretation of the role of low-salinity fluids of variable density as a metal transporting agent. Mass balance considerations based on chloride and copper budgets and the observation of retrograde quartz dissolution during copper mineralisation at Bingham (Landtwing et al., 2005) indicate that the cooling and expanding vapour phase was in fact the dominant copper-depositing ore fluid, whereas the coexisting brine is a good monitor of temperature control but probably contributed less than $20 \%$ to the total copper contained in this giant deposit (Williams-Jones and Heinrich, 2005).

Selective partitioning of $\mathrm{Au}, \mathrm{H}_{2} \mathrm{~S}$ and $\mathrm{SO}_{2}$ into the high-temperature magmatic vapour phase and subsequent contraction of this low-density vapour to an aqueous liquid is proposed to be the most effective process for generating gold-mineralizing epithermal ore fluids (Heinrich et al., 1999, 2004). Recent, unpublished data from several epithermal gold deposits of intermediate to high sulfidation state confirm their formation from exceptionally gold rich fluids, whose gold content of $\sim 1 \mathrm{ppm}$ is about three orders of magnitude higher than the gold solubility permitted by buffering of a crustal fluid of similar salinity in equilibrium with common rock-forming $\mathrm{Na}-\mathrm{K}-\mathrm{Ca}-\mathrm{Mg}-$ $\mathrm{Fe}$-silicates + quartz + pyrite at $250-350{ }^{\circ} \mathrm{C}$. These highly gold-enriched, low-salinity aqueous liquids were proba- 
bly generated by initial separation of a $\mathrm{Cu}-\mathrm{S}-\mathrm{Au}-$ rich vapour phase from a Na-K-Fe-Cl-rich brine, and subsequent cooling and contraction of the vapour to an aqueous liquid, which is a natural consequence of fluid cooling at pressures above the critical curve of the binary $\mathrm{NaCl}-\mathrm{H}_{2} \mathrm{O}$ fluid system. Moreover, field observations and thermodynamic modelling indicate that the gold-rich fluids cool along focussed channelways allowing limited reaction of the fluids with common silicate wall rocks (i.e., veins enveloped by alteration halos with high-variance assemblages of pyrophyllite/kalolinite \pm muscovite + quartz + pyrite). Epithermal gold ore deposition then occurs by a variety of disequilibrium processes, such as renewed exposure of the fluid to unaltered rock upon brecciation (leading to gold and pyrite deposition by fluid de-sulfidation), or by reduction of the initially moderately oxidised fluid $\left(\mathrm{SO}_{4}^{2-} \sim \mathrm{H}_{2} \mathrm{~S}\right)$ due to mixing with a reductant in a carbonaceous sedimentary environment (Heinrich, 2005).

This new interpretation of epithermal gold mineralisation, based on the combination of fluid inclusion microanalysis and multicomponent solubility calculation, illustrates the principle that the most efficient ore-forming processes involve a combination of selective metal enrichment by a specific (although not particularly unusual) source process, partial disequilibrium of the fluids with crustal rock buffers along their transport path (which ideally leads to progressive undersaturation, preventing dispersion of the metal load along the entire transport path) and a final process of ore deposition, where a large and focussed flux of metal rich fluid is forced to change its composition by sharp chemical disequilibrium within a new geological environment.

\section{EXPERIMENTAL STUDIES USING HIGH-P-T FLUID TRAPPING}

The preceding sections illustrate how natural hydrothermal processes can be studied by combining quantitative microanalytical data from fluid inclusions with experimentally determined thermodynamic data. The same analytical techniques have also opened new approaches to experimental laboratory studies of fluid - mineral - melt systems at high pressures and temperatures. Fluids can be sampled at experimental conditions, with minimal or no disturbance of the system, by trapping them as synthetic inclusions in minerals, as bubbles in silicate melts, or in interstices of fine diamond grit resisting mechanical compaction even at mantle pressures and temperatures. Subsequent analysis of the isolated fluid phase by microPIXE or LA-ICPMS allows determination of solubilities and distribution coefficients at high $P$ and $T$ (e.g., Ballhaus et al., 1994; Loucks and Mavrogenes, 1999, Stalder et al., 2000; Simon et al., 2003).

It is even possible to trap more or less separate samples of multiple coexisting fluid phases such as a vapour and a brine, which by nature are not quenchable. Thus, the first equilibrium distribution constants for $\mathrm{Na}, \mathrm{K}, \mathrm{Fe}$, $\mathrm{Cu}$ and $\mathrm{Au}$ between chloride-rich brine and vapour at upper-crustal magmatic conditions were obtained, using LA-ICPMS microanalysis of liquid and vapour trapped in quartz (Simon et al., 2004). As expected from thermodynamic theory and microanalysis of natural 'boiling trails' (Heinrich et al., 1999; Fig. 2), the degree of fractionation of all minor elements diminishes as conditions approach the critical point of the $\mathrm{H}_{2} \mathrm{O}-\mathrm{NaCl}$-dominated fluid systems. Also, as predicted from field-based observation of natural inclusions, the partitioning of $\mathrm{Cu}$ into the vapour phase increases as sulphur is added to the experimental system (Simon et al., 2005).

\section{APPLICATION TO SUBDUCTION ZONE FLUIDS}

Figure 3 summarises the main results from two microanalytical studies of experimental and natural fluids at uppermantle conditions, relevant to the transport of volatile and incompatible lithophile elements from the subducted oceanic lithosphere to the zone of calcalkaline melt generation in the overriding mantle wedge. Kessel et al. (2005) recently presented experimental distribution coefficients

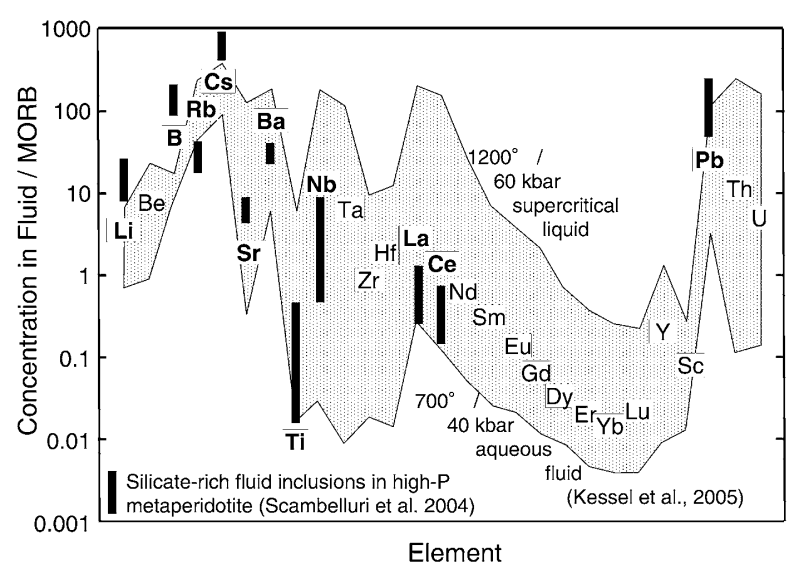

Figure 3. Summary of experimental distribution coefficients between aqueous fluids or supercritical $\mathrm{H}_{2} \mathrm{O}^{-}$-silicate liquids, as determined by trapping the mobile phase in synthetic diamond aggregate at upper mantle conditions (grey shaded envelope of 6 experiments; Kessel et al., 2005), in comparison with natural fluid inclusions found in high-pressure metaperidotites [vertical bars showing range of averages among 5 inclusion assemblages from Scambelluri et al. (2004); absolute scaling uncertain; data normalised to N-MORB using values from Sun and McDonough (1989) and Chaussidon and Jambon (1994) for B]. Both the synthetic and the natural subduction zone fluids were analysed by LA-ICPMS microanalysis at ETH Zürich. 
in a system of excess water and a trace-element-doped synthetic mid-ocean ridge basalt. The results show a transition from two phases, a coexisting silicate melt and a hydrothermal fluid at $40 \mathrm{kbar}$, to a single-phase supercritical liquid of continuously varying silicate/water ratio at $60 \mathrm{kbar}$ and $700-1200{ }^{\circ} \mathrm{C}$. The variably silicate-rich mobile phase (aqueous fluid or supercritical liquid) was trapped in diamond aggregate during equilibration with a basaltic eclogite assemblage \pm melt in a rocking multianvil apparatus. After quenching, the small gold capsule was frozen in liquid nitrogen, prior to opening and immediate LA-ICPMS analysis of the fluid-saturated diamond aggregate in the frozen state. The results span a range of element concentrations depending on $P, T$ and fluid type, as shown by the grey shaded band in Figure 3 . The minor and trace element patterns resemble the "subduction signature' of primitive arc magmas: enrichment in volatile (B, $\mathrm{Li})$ and large-ion lithophile elements $(\mathrm{Rb}, \mathrm{Cs}, \mathrm{Sr}, \mathrm{Ba}, \mathrm{Pb}$, $\mathrm{Th}, \mathrm{U}$ ), depletion in high-field-strength element (Ti, $\mathrm{Zr}$, $\mathrm{Hf}$, as well as $\mathrm{Nb}$ and $\mathrm{Ta}$ in the aqueous fluids and supercritical liquids, except at the highest temperatures), and typical steep REE trends.

The experimental 'fluids' are compositionally similar to selected element abundances analysed by LA-ICPMS in natural fluid inclusions trapped in deeply subducted ophiolitic metaperidotites (Scambelluri et al., 2004; Fig. 3 ). These inclusions were found in metamorphic olivine, as heterogeneous phase mixtures at ambient conditions composed of a low-salinity aqueous solution and numerous silicate phases. They are thought to have precipitated from an originally homogeneous, highly silicate-rich fluid trapped at mantle pressures and temperatures during subduction of serpentinite or on the return path of the metaperidotites to the Earth's surface. The similarity of the natural fluids with the synthetic 'slab fluids' of Kessel et al. (2005) - with regard to strong $\mathrm{Li}, \mathrm{B}, \mathrm{Rb}, \mathrm{Cs}$ and $\mathrm{Pb}$ enrichment, moderate enrichment of $\mathrm{Sr}$ and light $\mathrm{REE}$ (heavy REE were below detection) and the strong depletion in Ti compared to N-MORB - confirm the interpretation that these natural fluids record a chemical memory of subduction-zone metamorphism (Scambelluri et al., 2004 and earlier papers cited therein). In fact, the correspondence is closer than expected, considering that the natural fluids were equilibrated with a previously serpentinised harzburgite, rather than an ocean floor basalt, and given the fact that absolute concentrations in the natural low ${ }^{-}$ salinity fluids are subject to a highly uncertain internal standardisation.

\section{CONCLUDING REMARKS}

In the classical period of hydrothermal geochemistry between 1960 and 1980, the essentials of metamorphic fluid-rock reaction, magmatic fluid exsolution and the formation of hydrothermal ore deposits were successfully deduced from a combination of geological field observation and experimental studies of mineral-fluid-melt equilibria. Fluids from active hydrothermal systems, accessible for direct sampling and bulk analysis, provided the only opportunity for quantitative field testing of fluidmineral interactions, and also served as an important source of intuition about ore-forming processes (e.g., Barnes, 1979). With the advent of highly sensitive analyses of major to trace-element concentrations in microscopic inclusions trapped in natural minerals, we are now in a position to test our understanding of hydrothermal processes, without a priori assumptions of chemical equilibrium, and at pressure and temperature conditions far out of reach for direct fluid sampling. New and more predictive models for hydrothermal mass transfer and ore formation will increasingly combine field-based data about palaeofluid compositions in space and time with fluiddynamic transport simulations and experimental kinetic and thermochemical data.

The quality of our fluid compositional analyses, in laboratory investigations as well as in studies of natural systems, remains central to all future new insights. It requires continued technical development as well as a critical evaluation of the significance and uncertainty limits in the analytical results.

\section{ACKNOWLEDGMENTS}

I would like to thank Thomas Pettke and other members of ETH's Fluids and Mineral Deposits Group for their continued contribution of ideas and excellent new data that supported this summary paper. Careful reviews of this manuscript by Koichiro Fuijimoto and Jacob Hanley are gratefully acknowledged.

\section{REFERENCES}

Allan, M.M., Yardley, B.W.D., Forbes, L.J., Shmulovich, K.I., Banks, D.A. and Shepherd, T.J. (2005) Validation of LAICP-MS fluid inclusion analysis with synthetic fluid inclusions. American Mineralogist, 90, 1767-1775.

Audétat, A., Günther, D. and Heinrich, C.A. (1998) Formation of a magmatic-hydrothermal ore deposit: insights with LAICP-MS analysis of fluid inclusions. Science, 279, 20912094.

Ballhaus, C., Ryan, C.G., Mernagh, T.P. and Green, D.H. (1994) The Partitioning of $\mathrm{Fe}, \mathrm{Ni}, \mathrm{Cu}, \mathrm{Pt}$, and $\mathrm{Au}$ between Sulfide, 
Metal, and Fluid Phases - a Pilot-Study. Geochimica et Cosmochimica Acta, 58, 811-826.

Barnes, H.L. (1979) Geochemistry of Hydrothermal Ore Deposits, $2^{\text {nd }}$ ed. pp. 499, John Wiley \& Sons, New York.

Cauzid, J., Philippot, P., Somogyi, A., Simionovici, A. and Bleuet, P. (2004) Quantification of single fluid inclusions by combining synchrotron radiation-induced $\mathrm{mu}^{-} \mathrm{X}$-ray fluorescence and transmission. Analytical Chemistry, 76, 3988-3994.

Chaussidon, M. and Jambon, A. (1994) Boron Content and Isotopic Composition of Oceanic Basalts - Geochemical and Cosmochemical Implications. Earth and Planetary Science Letters, 121, 277-291.

Dietrich, A., Lehmann, B. and Wallianos, A. (2000) Bulk rock and melt inclusion geochemistry of Bolivian tin porphyry systems. Economic Geology, 95, 313-326.

Günther, D., Audétat, A., Frischknecht, R. and Heinrich, C.A. (1998) Quantitative analysis of major, minor and trace elements in fluid inclusions using laser ablation inductively coupled plasma mass spectrometry. Journal of Analytical Atomic Spectrometry, 13, 263-270.

Halter, W., Heinrich, C. and Pettke, T. (2005) Magma evolution and the formation of porphyry $\mathrm{Cu}-\mathrm{Au}$ ore fluids: evidence from silicate and sulfide melt inclusions. Mineralium Deposita, 39, 845-863.

Heinrich, C. (2005) The physical and chemical evolution of lowsalinity magmatic fluids at the porphyry to epithermal transition: a thermodynamic study. Mineralium Deposita, 39, 864889.

Heinrich, C.A., Ryan, C.G., Mernagh, T.P. and Eadington, P.J. (1992) Segregation of ore metals between magmatic brine and vapor - a fluid inclusion study using PIXE microanalysis. Economic Geology, 87, 1566-1583.

Heinrich, C.A., Günther, D., Audétat, A., Ulrich, T. and Frischknecht, R. (1999) Metal fractionation between magmatic brine and vapor, determined by microanalysis of fluid inclusions. Geology, 27, 755-758.

Heinrich, C.A., Pettke, T., Halter, W.E., Aigner-Torres, M., Audetat, A., Günther, D., Hattendorf, B., Bleiner, D., Guillong, M. and Horn, I. (2003) Quantitative multi-element analysis of minerals, fluid and melt inclusions by laser-ablation inductively-coupled-plasma mass- ${ }^{-}$spectrometry. Geochimica et Cosmochimica Acta, 67, 3473-3497.

Heinrich, C.A., Driesner, T., Stefansson, A. and Seward, T.M. (2004) Magmatic vapor contraction and the transport of gold from the porphyry environment to epithermal ore deposits. Geology, 32, 761-764.

Hemley, J.J., Cygan, G.L., Fein, J.B., Robinson, G.R. and Dangelo, W.M. (1992) Hydrothermal ore-forming processes in the light of studies in rock-buffered systems. 1. Iron-copper-zinc-lead sulfide solubility relations. Economic Geology, $87,1-22$.

Hezarkhani, A., Williams-Jones, A.E. and Gammons, C.H. (1999) Factors controlling copper solubility and chalcopyrite deposition in the Sungun porphyry copper deposit, Iran. Mineralium Deposita, 34, 770-783.

Kessel, R., Schmidt, M.W., Ulmer, P. and Pettke, T. (2005) Trace element signature of subduction-zone fluids, melts and supercritical liquids at $120-180 \mathrm{~km}$ depth. Nature, 437, 724-727.

Klemm, L., Pettke, T. and Heinrich, C.A. (2006) Early magmatichydrothermal evolution of the Questa porphyry Mo deposit, New Mexico, USA. Mineralium Deposita (submitted).
Landtwing, M.R., Pettke, T., Halter, W.E., Heinrich, C.A., Redmond, P.B., Einaudi, M.T. and Kunze, K. (2005) Copper deposition during quartz dissolution by cooling magmatichydrothermal fluids: The Bingham porphyry. Earth and Planetary Science Letters, 235, 229-243.

Loucks, R.R. and Mavrogenes, J.A. (1999) Gold solubility in supercritical hydrothermal brines measured in synthetic fluid inclusions. Science, 284, 2159-2163.

Proffett, J.M. (2003) Geology of the Bajo de la Alumbrera porphyry copper-gold deposit, Argentina. Economic Geology, 98, 1535-1574, including 4 Map Supplements.

Redmond, P.B., Einaudi, M.T., Inan, E.E., Landtwing, M.R. and Heinrich, C.A. (2004) Copper ore formation by fluid cooling in porphyry copper deposits: new insights from cathodoluminescence petrography combined with fluid inclusion microthermometry. Geology, 32, 217-220.

Rusk, B. and Reed, M. (2002) Scanning electron microscopecathodoluminescence analysis of quartz reveals complex growth histories in veins from the Butte porphyry copper deposit, Montana. Geology, 30, 727-730.

Ryan, C.G. (2004) Ion beam microanalysis in geoscience research. Nuclear Instruments \& Methods in Physics B, 219-20, 534549.

Scambelluri, M., Fiebig, J., Malaspina, N., Muntener, O. and Pettke, T. (2004) Serpentinite subduction: Implications for fluid processes and trace-element recycling. International Geology Review, 46, 595-613.

Simon, A.C., Pettke, T., Candela, P.A., Piccoli, P.M. and Heinrich, C.A. (2003) Experimental determination of Au solubility in rhyolite melt and magnetite: Constraints on magmatic Au budgets. American Mineralogist, 88, 1644-1651.

Simon, A.C., Pettke, T., Candela, P.A., Piccoli, P.M. and Heinrich, C.A. (2004) Magnetite solubility and iron transport in magmatic-hydrothermal environments. Geochimica et Cosmochimica Acta, 68, 4905-4914.

Simon, A.C., Pettke, T., Candela, P., Piccoli, P. and Heinrich, C. (2005) The effect of volatile sulfur on metal partitioning at magmatic conditions. Geochimica et Cosmochimica Acta, 69, A657-A657.

Stalder, P., Ulmer, P., Thompson, A.B. and Günther, D. (2000) Experimental approach to constrain second critical end points in fluid/silicate systems: Near-solidus fluids and melts in the system albite- $\mathrm{H}_{2} \mathrm{O}$. American Mineralogist, 85, 68-77.

Sun, S.S. and McDonough, W.F. (1989) Chemical and isotopic systematics of oceanic basalts: implications for mantle composition and processes. In Magmatism in the ocean basins, (Saunders, A.D. and Norry, M.J. Eds.). Geological Society (London) Special Publication, 42, 313-345.

Ulrich, T., Günther, D. and Heinrich, C.A. (1999) Gold concentrations of magmatic brines and the metal budget of porphyry copper deposits. Nature, 399, 676-679.

Ulrich, T., Günther, D. and Heinrich, C.A. (2001) The evolution of a porphyry $\mathrm{Cu}-\mathrm{Au}$ deposit, based on LA-ICP-MS analysis of fluid inclusions: Bajo de la Alumbrera, Argentina, correctly re-printed in Economic Geology, 97, 1888-1920.

Vanko, D.A., Bonnin-Mosbah, M., Philippot, P., Roedder, E. and Sutton, S.R. (2001) Fluid inclusions in quartz from oceanic hydrothermal specimens and the Bingham, Utah porphyryCu deposit: a study with PIXE and SXRF. Chemical Geology, 173, 227-238

Williams-Jones, A.E. and Heinrich, C.A. (2005) Vapor transport 
of metals and the formation of magmatic-hydrothermal ore deposits. Economic Geology, invited 100th Anniversary Paper, 100, 1287-1312.

Williams-Jones, A.E., Migdisov, A.A., Archibald, S.M. and Xiao, Z.F. (2002) Vapor-transport of ore metals. In Water-rock interaction: a tribute to David A. Crerar (Hellmann, R. and Wood, S.A. Eds.). The Geochemical Society, Special Publication 7, 279-305.
Yardley, B.W.D. (2005) 100th Anniversary Special Paper: Metal concentrations in crustal fluids and their relationship to ore formation. Economic Geology, 100, 613-632.

Manuscript received March 21, 2006

Manuscript accepted March 31, 2006

Manuscript handled by Koichiro Fujimoto 